\title{
BMJ Open Burnout as a correlate of depression among medical students in Cameroon: a cross-sectional study
}

\author{
Tsi Njim, ${ }^{1,2}$ Clarence Mvalo Mbanga, ${ }^{3}$ Maxime Tindong, ${ }^{4}$ Steve Fonkou, ${ }^{5}$ \\ Haman Makebe, ${ }^{5}$ Louise Toukam, ${ }^{6}$ Johnson Fondungallah, ${ }^{7}$ Azingala Fondong, ${ }^{5}$ \\ Isabelle Mulango, ${ }^{8}$ Belmond Kika ${ }^{9}$
}

To cite: Njim T, Mbanga CM, Tindong $\mathrm{M}$, et al. Burnout as a correlate of depression among medical students in Cameroon: a cross-sectional study. BMJ Open 2019;9:e027709. doi:10.1136/ bmjopen-2018-027709

- Prepublication history and additional material for this paper are available online. To view these files, please visit the journal online (http://dx.doi. org/10.1136/bmjopen-2018027709).

Received 4 November 2018 Revised 8 February 2019 Accepted 1 March 2019
Check for updates

(C) Author(s) (or their employer(s)) 2019. Re-use permitted under CC BY-NC. No commercial re-use. See rights and permissions. Published by BMJ.

For numbered affiliations see end of article.

Correspondence to

Dr Tsi Njim; tsinjim@gmail.com

\section{ABSTRACT}

Objective Burnout syndrome has been shown to mediate the pathway between job stress and depression. This study aims to assess the relationship between the various components of burnout syndrome and depression; and to determine the contribution of other sociodemographic variables to depression among medical students in Cameroon.

Design A cross-sectional study.

Setting Three of the five medical schools in Cameroon with students in both preclinical and clinical levels of studies.

Participants The study included 413 consenting medical students.

Primary outcome measure Data were collected via a printed self-administered questionnaire. The primary outcome-depression was assessed using the Patient Health Questionnaire-9 (PHQ-9). Burnout was assessed using the Oldenburg Burnout Inventory. Multivariable linear regression was used to identify independent correlates of depression.

Results The overall prevalence of depression (PHQ-9 $>4$ ) and major depressive disorder ( $\mathrm{PHQ}-9>9)$ in these students was $66.34 \%$ and $23.00 \%$, respectively. After multivariable linear regression analysis, four variablestotal OLBI (beta $=0.32 ; 95 \% \mathrm{Cl} 0.22$ to $0.42 ; \mathrm{p}<0.001$ ); number of children (beta $=-2.26 ; 95 \% \mathrm{Cl}-3.70$ to $-0.81 ; p=0.002)$; occurrence of a life-changing crises (beta=1.29; $95 \% \mathrm{Cl} 0.13$ to $2.45 ; \mathrm{p}=0.029$ ) and presence of a chronic illness (beta $=3.19 ; 95 \% \mathrm{Cl} 0.96$ to 5.42 ; $\mathrm{p}=0.005$ ) significantly predicted depression in these students and explained $32.4 \%$ of the variance $\left(R^{2}=32.4\right.$, $F[14,204]=6.98, p<0.001)$. The emotional exhaustion component $\left(R^{2}=17.4, F[1,411]=86.39, p<0.001\right)$ explained more of the variance in depression than the disengagement component $\left(R^{2}=6.1, F[1,411]=26.76\right.$, $\mathrm{p}<0.001$ ) of burnout syndrome.

Conclusion The prevalence of depression among medical students in Cameroon is high. It is important that correlates of depression are identified early in medical students to limit progress to depression.

\section{INTRODUCTION}

Depression is a common mental disorder worldwide and a leading cause of disability with debilitating symptoms. ${ }^{1-3}$ Around

\section{Strengths and limitations of this study}

This study was carried out in all the medical schools in Cameroon that had both students in the clinical and preclinical phase of studies.

- This is the first study in sub-Saharan Africa that attempts to establish a relationship between burnout syndrome and depression.

- Due to the cross-sectional design of the study, the temporality of this relationship could not be ascertained.

350 million people suffer from depression globally with reports stating that almost $3.2 \%$ of individuals express having a depressive episode at least once in their lives. ${ }^{13}$ Evidence has shown that the prevalence of depression is higher in medical students than in the general population. A recent systematic review obtained an overall pooled crude prevalence of depression of $27.2 \%$ among medical students, ${ }^{4}$ while a recent study among medical students in Cameroon showed that $65.2 \%$ of medical students had provisional depression (Patient Health Questionnaire-9 [PHQ-9] $\geq 4$ ) and $30.6 \%$ of the students had PHQ-9 scores $\geq 10$, indicating the presence of a major depressive disorder. ${ }^{5}$

Burnout syndrome is a mental state characterised by emotional exhaustion and disengagement. ${ }^{6}$ The emotional component of the syndrome is commonly said to be related to depression in the work context. ${ }^{78}$ Students who face similar tasks and expected goals as professionals are likely to experience similar exhaustion and withdrawal from their studies. ${ }^{9-11}$ Previous research has shown likely associations between the traditional stressful path of academic life among medical students, with the tendency of them developing burnout syndrome, which further worsens during their future practice as doctors. $^{12-15}$ 
Bakker et al used the equity theory to establish a difference between burnout and depression. ${ }^{8}$ They determined from research that lack of reciprocity in work relationships directly influenced burnout but only indirectly influenced depression while lack of reciprocity in interpersonal relationships could directly influence depression. ${ }^{8}$ They concluded that burnout and depression were therefore separate constructs with burnout being mostly work-related and depression occurring in any context.

In a previous publication, we established that the predictors of burnout in a group of medical students were: cumulative grade point average of results, regretting choice of medical studies, marital status, difficulties in interpersonal relationships and recreational drug use. ${ }^{16}$ In this current report, we seek to determine the relationship between burnout and depression in these students and the various sociodemographic predictors which moderate the two constructs.

This could help to add to the growing cartography of mental health issues among this special population in Cameroon and could raise awareness on the need for detection of burnout and depression, and the investigation and institution of appropriate preventive strategies to curb the growing problem of mental disorders in Cameroon. ${ }^{17}$

\section{METHODS}

\section{Population and design}

Population, sampling and sample size:

This report is part of the Mental health for Liberia, Tanzania and Cameroon (Me-HeLTC) project and the methods used have been described in previous publications. ${ }^{16} 1819$ Three medical schools (University of Bamenda, University of Douala and University of Buea) were sampled from the five recognised medical schools in Cameroon with students in the clinical phases of study using a random sequence generator in order to reduce selection bias. This sampling strategy was used for convenience to reduce the costs of collecting information from all five medical schools. Consenting medical students were recruited from each medical school by a convenience sampling until the sample size was attained as calculated by the formula below ${ }^{20}$ :

$n=\frac{Z^{2} P(1-P)}{d^{2}}$ where $\mathrm{n}=$ sample size, $\mathrm{Z}=\mathrm{Z}$ statistic for a level of confidence, $\mathrm{P}=$ expected prevalence or proportion of depression (in proportion of one: $27.2 \% \%, \mathrm{P}=$ 0.272 ) , ${ }^{4}$ and $\mathrm{d}=$ precision (in proportion of one; if $5 \%, \mathrm{~d}$ $=0.05)$. Z statistic $(\mathrm{Z})$ : For the level of confidence of $5 \%$, which is conventional, $\mathrm{Z}$ value is 1.96 . For a $95 \%$ CIs.

A minimum of 305 medical students were required for the study. A total of 500 questionnaires were handed and 413 questionnaires were returned.

\section{Design}

The study was conducted from January 2018 to March 2018.

\section{Instrument}

Medical students were handed a three-part printed structured questionnaire consisting of:

Sociodemographic information associated with burnout and depression from literature-gender, level of studies and poor academic performance (average academic results). 4513 21-24

Sociodemographic information associated with burnout from literature-age, marital status, presence of dependants, duration of daily schedule invested in studies, difficulties in interpersonal relationships, monthly income, alcohol use (recreational drug use) and smoking. ${ }^{1321} 2224$

Sociodemographic information associated with depression from literature-suffering from a chronic illness and encountering a life-changing crisis in the past 6 months. ${ }^{523}$

Burnout syndrome was assessed using an adapted version of the OLdenburg Burnout Inventory (OLBI), a self-administered questionnaire consisting of 16 positively and negatively framed questions. ${ }^{6}{ }^{11}$ Responses on the OLBI range on a four-point Likert-scale from strongly agree to strongly disagree assessing two parameters of burnout syndrome-emotional exhaustion (eight questions) and disengagement (eight questions). Scores could range from 16 to 64 . Validated and reliable versions of the OLBI and PHQ-9 questionnaires in French ${ }^{25} 26$ were test-piloted for suitability before administration in the University of Douala where the primary language of teaching and examination is French.

The final section of the data collection tool assessed depression using the nine-item self-administered PHQ-9. ${ }^{27}$ The mental health professional reinterview showed that a PHQ-9 score $\geq 10$ had a good predictive value for the diagnosis of major depression. ${ }^{28}$

\section{Data management, statistical analysis, validity and reliability of} instruments

Data entry was done using EPI Info V.7 (CDC, Atlanta, Georgia, USA) and data analysis was carried out using Stata software package V.12 (Statacorp).

The two subscales of the OLBI (emotional exhaustion and disengagement) were used to define burnout. The reliability of the OLBI was assessed using the alpha Cronbach statistics. The alpha Cronbach statistic for emotional exhaustion items was 0.67 while that for disengagement items was 0.61 (online supplementary file 1 ). When both scales were combined, the reliability improved with an alpha Cronbach statistic of 0.74 showing that the OLBI was measuring a single construct in this population-burnout. ${ }^{16}$ Both subscales were therefore added to obtain a total score for burnout syndrome after negatively phrased items were reversed $(1=4,2=3,3=2,4=1)$ such that higher scores indicated higher exhaustion and disengagement.

A diagnosis of depression was made if PHQ-9 scores were greater than 4 . The severity of depression was determined using the following classification: mild: 5-9; moderate: $10-14$; moderately severe: $15-19$; and severe: $20-27 .^{28}$ The prevalence of depression among participants was 
calculated in these categories to ease comparison with previous research carried out in Cameroon. ${ }^{5}$ The reliability of the PHQ-9 questionnaire was also assessed using the alpha Cronbach coefficient and a statistic of 0.76 was obtained (online supplementary file 2).

A univariable linear regression analysis was performed using burnout as a continuous predictor variable on the OLBI scale and depression as a continuous outcome variable on the PHQ-9 scale to determine if burnout syndrome was a correlate of depression. Univariable linear regression analyses were also performed with sociodemographic and clinical variables as correlates. Variables with $\mathrm{p}$ values $<0.25^{29}$ on univariable analysis were inputted into a multivariable linear regression model to ascertain independent correlates for depression.

\section{Patient and public involvement}

Patients and the public were not involved in the design and recruitment process of the study.

\section{RESULTS}

\section{Sociodemographic characteristics}

A total of 500 questionnaires were handed out and 413 returned (response rate $=82.6 \%)$ with $159 \quad(38.50 \%)$ from the University of Bamenda, 172 (41.65\%) from the University of Buea and $82(19.85 \%)$ from the University of Douala. Most of the participants (97.04\%) were not legally married and $20.98 \%$ of those who were in a personal relationship expressed difficulties in these relationships (table 1). The mean age of the participants was $21.21 \pm 2.43$ years with the average income obtained monthly being $48.45 \pm 2.41$ US\$ (table 1 ). The average burnout score on the OLBI scale was $37.13 \pm 5.91$.

\section{Prevalence of depression}

The overall prevalence of depression in these students (PHQ-9 $>4$ ) was $66.34 \%$ (online supplementary file 3 ) and $23.00 \%$ of the students had a major depressive disorder (PHQ-9 $\geq 10$ ). For participants who admitted having problems on the PHQ-9 questionnaire, 228 (55.21\%), $22(5.33 \%)$ and $5(1.21 \%)$ expressed that handling these problems were 'somewhat difficult', 'very difficult' and 'extremely difficult' respectively.

\section{Correlates of depression}

After multivariable linear regression analysis, it was shown that four variables significantly predicted depression in these medical students and explained $32.4 \%$ of the variance $\left(R^{2}=32.4, F[14,204]=6.98, p<0.001\right)$. These variables were: total OLBI score (beta $=0.32 ; 95 \%$ CI 0.22 to 0.42 ; $\mathrm{p}<0.001$ ); number of children (beta $=-2.26$; 95\% CI -3.70 to $-0.81 ; \mathrm{p}=0.002)$; occurrence of a life-changing crises (beta $=1.29 ; 95 \%$ CI 0.13 to $2.45 ; \mathrm{p}=0.029$ ) and presence of a chronic illness (beta $=3.19 ; 95 \%$ CI 0.96 to 5.42 ; $\mathrm{p}=0.005)$ (table 1 ).

Analysis of the separate components of the OLBI score showed that the emotional exhaustion component
$\left(\mathrm{R}^{2}=17.4, \quad \mathrm{~F}[1,411]=86.39, \mathrm{p}<0.001\right)$ explained more of the variance in depression than the disengagement component $\left(\mathrm{R}^{2}=6.1, \mathrm{~F}[1,411]=26.76, \mathrm{p}<0.001\right)$.

\section{DISCUSSION}

In this study, we determined that the prevalence of depression among medical students in Cameroon was $66.34 \%$. Independent correlates of depression included: number of children, presence of a chronic illness, occurrence of a life-changing crises and burnout syndrome assessed by the total OLBI score.

A recent study showed that $65.2 \%$ of medical students in Cameroon had a provisional diagnosis of depression with a third of these students (30.5\%) having a major depressive disorder. ${ }^{5}$ This is quite similar to the prevalence of depression (66.34\%) and major depressive disorder $(23.00 \%)$ in our study. The former study included four universities in the country-the University of Buea, University of Bamenda, University of Yaounde I and the University of Douala; while our study included three of these universities (University of Bamenda, University of Buea and University of Douala). Both studies also included students in both the preclinical and clinical phases of studies. These similar results emphasise the high prevalence of depression in this special population who lack access to mental health services in the country.

Similar levels of depression among medical students have been reported elsewhere in Africa. ${ }^{30-32}$ These similarities further point out the stressful and demanding nature of medical studies irrespective of the region or country of training. The demanding nature of the training, alongside the numerous years of studies involved probably contribute to the high levels of depression noted among medical students. This is made worse as most medical schools in sub-Saharan Africa do not have strategies put in place, as well as assigned mental health personnel for the identification, follow-up and management of such cases. As a result, students faced with such difficulties find themselves using inappropriate practices to cope with the condition, with just a very small proportion of them seeking proper help from qualified mental health personnel. $^{30}$

Burnout syndrome was found to be a correlate of depression in our study. It is increasingly being recognised as a significant mental health issue in global health. ${ }^{33}$ However, like several mental health disorders, this syndrome among others is neglected in developing countries and in Cameroon in particular. ${ }^{34} 35$

There is however an ongoing debate about the overlap of these constructs (burnout and depression). The WHO classified burnout (coded as 'Z73.0, Problems related to life management difficulty') as a distinct condition defined as a 'state of vital exhaustion' and it includes mental and physical exhaustion related to stress at work, in the International Classification of Diseases, 10th revision. ${ }^{36}$ We agree that there is no clear diagnosis for burnout unlike depression. 
Open access

Table 1 Multiple linear regression analysis of predictors of depression among 413 medical students in Cameroon from January to March 2018

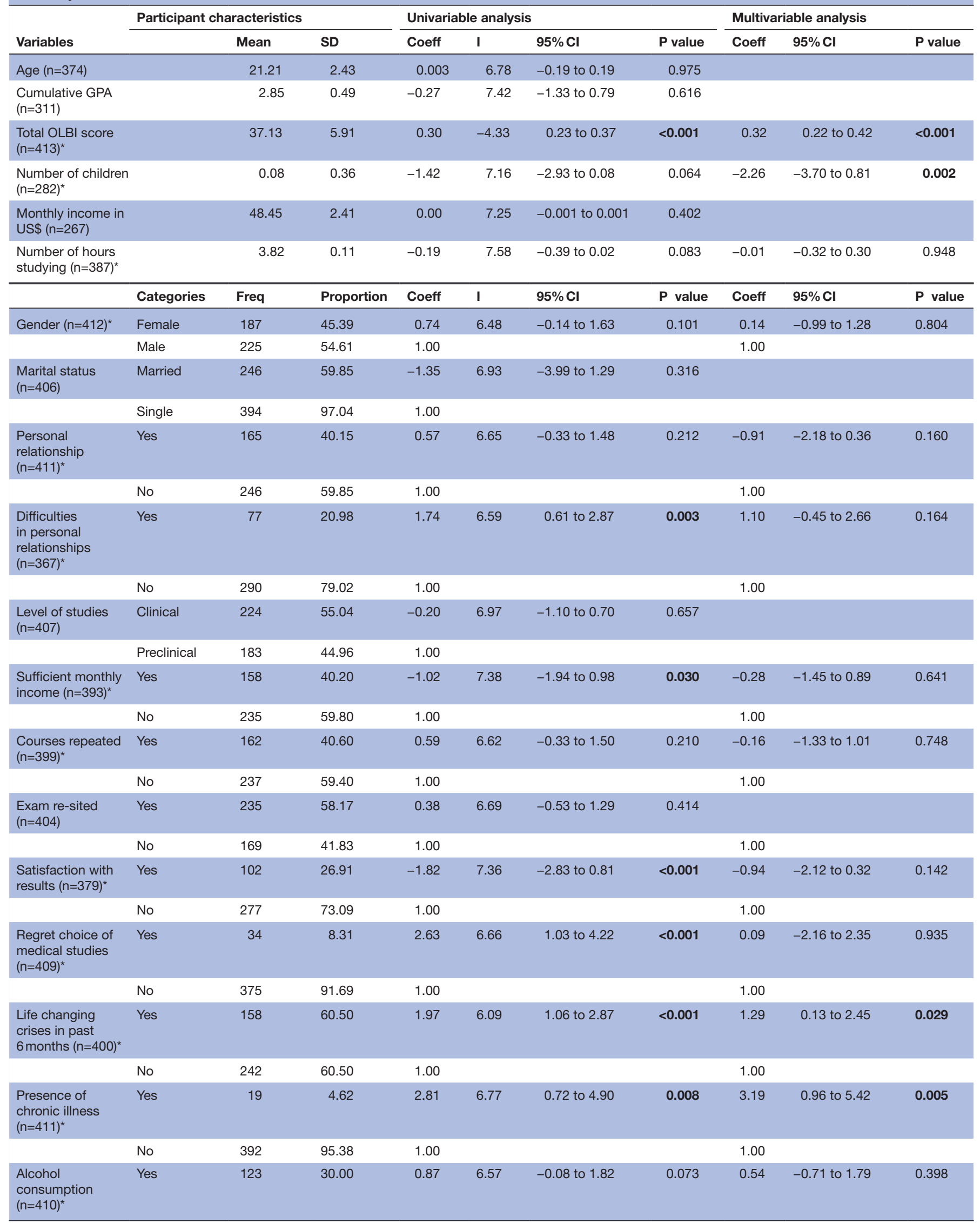

Continued 


\begin{tabular}{|c|c|c|c|c|c|c|c|c|c|c|}
\hline & Categories & Freq & Proportion & Coeff & 1 & $95 \% \mathrm{Cl}$ & $P$ value & Coeff & $95 \% \mathrm{Cl}$ & $P$ value \\
\hline & No & 287 & 70.00 & 1.00 & & & & 1.00 & & \\
\hline $\begin{array}{l}\text { Recreational drug } \\
\text { use }(n=408)^{*}\end{array}$ & No & 399 & 97.79 & 1.00 & & & & 1.00 & & \\
\hline
\end{tabular}

Bold values indicate statistically significant variables ( $p$ value $<0.05$ ).

*Variables included in multivariable analysis.

coeff, coefficient; GPA, grade point average; I, intercept; OLBI, OLdenburg burnout inventory.

However, it is agreed that prolonged stressful work environments put individuals in conditions where they could feel emotionally empty and unable to cope. ${ }^{37}$ It is more regularly advanced that burnout should be regarded as a separate construct from depression as the instruments generally used to measure burnout highlight that the problems arising from the condition are purely 'work-related' and the individual exhibits withdrawal from work whereas with depression, the instruments highlight that there are negative thoughts and feelings about other aspects in life in general. ${ }^{37}$

Using the equity theory, Bakker et al showed that these two constructs were entirely different. ${ }^{8}$ In their research, they showed that lack of reciprocity in work relationships directly influenced burnout, and hence burnout was exclusively related to the workplace; while lack of reciprocity in interpersonal relationships directly influence depression which was only indirectly influenced by lack of reciprocity in the workplace-hence the possibility of depression being context-free. They further postulated that burnout was associated with depression and the emotional component of burnout syndrome was particularly responsible for depressive symptoms. ${ }^{8}$

Our results seem to agree with the above theory to a certain extent. From our previous publication, a student's results (measured as their cumulative grade point average) and regretting their choice of medical studies, which could be characterised as job-related stressors significantly predicted burnout in this group of medical students. ${ }^{16}$ Other predictors of burnout in these students were-marital status and relationship difficulties. $^{16}$ Though these variables are not work-related

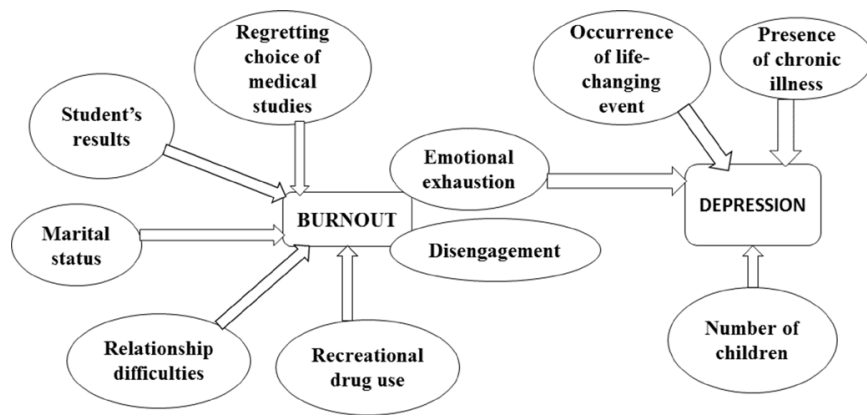

Figure 1 Theoretical framework describing relationship between sociodemographic variables, burnout and depression. or studies-related, they may be regarded as emotional stressors that influence burnout. It was shown in this analysis that the emotional component of burnout explained the variance in depression better than the disengagement component. Also, the predictors of depression, identified in this study: number of children, presence of a chronic illness and occurrence of a life-changing crises show that depression is as a result of negative life events and trauma as confirmed by Bouma et $a l^{88}$ and occurs relatively context-free (figure 1).

Similar findings were observed in a group of patients by Chiu et al in $2015 .^{39}$ Despite using different questionnaires to assess depression and burnout, it was found that burnout scores strongly correlated with depressive symptoms. Also, Bullock et al in a worldwide systematic review in 2017 described a positive relationship that existed between burnout and depressive symptoms in graduate healthcare students. ${ }^{40}$ However, the temporality of the relationship is still a topic of debate as there has not been any established direction. For instance, Frank et al in 2017 described a bidirectional relationship in junior elite athletes. ${ }^{41}$

The association between burnout and depression is further worrying as in this setting, the situation may get worse when these students leave medical school due to the high 'low physician-patient' ratio that awaits them; low remuneration; inability to practice with professional autonomy; limited career advancement opportunities and limited appropriate equipment for effective practice-all conditions which are prevalent in Cameroon. ${ }^{42}$

The presence of a chronic illness was also found to be a correlate of depression in our study. The occurrence of depression in chronic illness is usually a consistent finding. Some chronic illnesses like cerebrovascular diseases and Parkinson's disease have biological effects which directly influence a progress to depression while in most instances, the debilitating effects of the chronic illness limiting the patient's ability to participate in daily and previously appealing activities could lead to them becoming depressed. ${ }^{43}$ In medical students who are expected to perform tremendous task loads; having to deal with the pressure, stress and demands of medical studies as well as the daily challenges that come with managing most chronic diseases and a family (husband/wife and children) will imply that such students have a double or even a triple dose of burden to deal or cope with. This will mean more effort and consequently quicker exhaustion, 
culminating ultimately to the development of burnout and/or depression. This is a vicious cycle, as depression has been shown to negatively affect the compliance to treatment of such chronic illnesses. ${ }^{44}{ }^{45}$ Poor management of any ongoing illness will mean poor health and consequently the inability to meet up with the physical and mental demands of medical studies. This could lead to poor performances and further aggravation of depression. All these highlight the need to develop programmes aimed at regularly evaluating the mental health status of medical students and providing the necessary resources for their treatment and follow-up.

\section{Limitations}

Due to the cross-sectional design, temporal associations and causality cannot be ascertained. It will therefore be important for longitudinal studies to ascertain if burnout occurs before depression and could inherently lead to the latter. The various definitions of burnout and depression using questionnaires like the OLBI inventory and the PHQ-9 questionnaire need to be evaluated in the cultural context of different populations in Cameroon.

Nevertheless, to the best of our knowledge, it is the first study in Cameroon that describes the relationship between burnout and depression. Further research on this topic is therefore warranted to ascertain the direction of the relationship. Also, the sampling strategy used limited selection bias of the universities and the high response rate obtained provides certainty in the results.

\section{CONCLUSIONS}

The prevalence of depression among medical students in Cameroon is high. It is important that correlates of depression which include burnout syndrome, presence of a chronic illness and number of children that a student has are identified early to limit progression to depression in these students. Also, there is a need for the institution of basic mental healthcare facilities in medical schools in the country to help curb the morbidity associated with this condition.

\section{Author affiliations}

${ }^{1}$ Department of International Public Health, Liverpool School of Tropical Medicine, Liverpool, United Kingdom

${ }^{2}$ Research Group, Health and Human Development (2HD), Douala, Cameroon

${ }^{3}$ Surgical Unit, Mankon Sub-divisional Hospital, Bamenda, Cameroon

${ }^{4}$ Research Group, Clinical Research Education Networking and Consultancy, Douala, Cameroon

${ }^{5}$ Faculty of Health Sciences, University of Buea, Buea, Cameroon

${ }^{6}$ Faculty of Health Sciences, University of Bamenda, Bamenda, Cameroon

${ }^{7}$ Surgical Unit, Buea Town Medical Centre, Buea, Cameroon

${ }^{8}$ Internal Medicine Department, District Hospital Kumba, Kumba, Cameroon

${ }^{9}$ Internal Medicine Department, District Hospital Ekondo-Titi, Ekondo-Titi, Cameroon

Contributors Conception of study: TN. Literature review: TN, CMM, MT, IM, AF. Data collection: HM, LT, SF, JF, BK. Data management: SF. Data analysis: TN. Write-up of initial manuscript: TN, CMM, MT. Manuscript revisions: TN, CMM, MT, SF, HM, LT, JF, AF, IM, BK. All authors read and approved of the final manuscript.

Funding The authors have not declared a specific grant for this research from any funding agency in the public, commercial or not-for-profit sectors.

Competing interests None declared.
Patient consent for publication Not required.

Ethics approval Ethical and administrative approval were obtained from the Cameroon Baptist Health Board Institutional Review Board and the regional delegation of Public Health of the South west region, respectively.

Provenance and peer review Not commissioned; externally peer reviewed.

Data sharing statement The datasets during and/or analysed during the current study are available from the corresponding author on reasonable request.

Open access This is an open access article distributed in accordance with the Creative Commons Attribution Non Commercial (CC BY-NC 4.0) license, which permits others to distribute, remix, adapt, build upon this work non-commercially, and license their derivative works on different terms, provided the original work is properly cited, appropriate credit is given, any changes made indicated, and the use is non-commercial. See: http://creativecommons.org/licenses/by-nc/4.0/.

\section{REFERENCES}

1. Moussavi S, Chatterji S, Verdes E, et al. Depression, chronic diseases, and decrements in health: results from the world health surveys. Lancet 2007;370:851-8.

2. Kessler RC, Aguilar-Gaxiola S, Alonso J, et al. The global burden of mental disorders: an update from the WHO World Mental Health (WMH) surveys. Epidemiol Psichiatr Soc 2009;18:23-33.

3. Marcus M, Yasamy MT, van Ommeren M, et al. Depression: a global public health concern. WHO Department of Mental Health and Substance Abuse 2012;1:6-8.

4 Rotenstein LS, Ramos MA, Torre M, et al. Prevalence of depression, depressive symptoms, and suicidal ideation among medical students: a systematic review and meta-analysis. JAMA 2016;316:2214-36.

5. Ngasa SN, Sama CB, Dzekem BS, et al. Prevalence and factors associated with depression among medical students in Cameroon: a cross-sectional study. BMC Psychiatry 2017;17:216.

6 Demerouti E, Bakker AB. The oldenburg burnout inventory: a good alternative to measure burnout and engagement handbook of stress and burnout in health care. Utretch: Utretch University, 2008.

7 Ahola K, Honkonen T, Kivimäki M, et al. Contribution of burnout to the association between job strain and depression: the health 2000 study. J Occup Environ Med 2006;48:1023-30.

8 Bakker AB, Schaufeli WB, Demerouti E, et al. Using equity theory to examine the difference between burnout and depression. Anxiety, Stress \& Coping 2000;13:247-68.

9. Schaufeli WB, Martínez IM, Pinto AM, et al. Burnout and engagement in university students. A cross-national study. Journal of CrossCultural Psychology 2002;33:464.

10. Schaufeli WB, Taris TW. The conceptualization and measurement of burnout: Common ground and worlds apart. Work and Stress 2005; 19:256-62.

11 Reis D, Xanthopoulou D, Tsaousis I. Measuring job and academic burnout with the Oldenburg Burnout Inventory (OLBI): Factorial invariance across samples and countries. Burn Res 2015;2:8-18.

12. de Cavalcante Almeida G, de Souza HR, de Almeida PC, et al. The prevalence of burnout syndrome in medical students. Arch Clin Psychiatry 2016;43.

13 Costa EF, Santos SA, Santos AT, et al. Burnout Syndrome and associated factors among medical students: a cross-sectional study. Clinics 2012;67:573-9.

14 Dyrbye LN, West CP, Satele D, et al. Burnout among U.S. medical students, residents, and early career physicians relative to the general U.S. population. Acad Med 2014;89:443-51.

15 Ishak WW, Lederer S, Mandili C, et al. Burnout during residency training: a literature review. J Grad Med Educ 2009;1:236-42.

$16 \mathrm{Njim} \mathrm{T}$, Makebe H, Toukam L, et al. Burnout syndrome amongst medical students in cameroon: a cross-sectional analysis of the determinants in preclinical and clinical students. Psychiatry $J$ 2019;2019:1-7.

17. Keugoung B, Kongnyu ET, Meli J, et al. Profile of suicide in rural Cameroon: are health systems doing enough? Trop Med Int Health 2013;18:985-92.

18. Mbanga CM, Efie DT, Aroke D, et al. Prevalence and predictors of recreational drug use among medical and nursing students in Cameroon: a cross sectional analysis. BMC Res Notes 2018;11:515.

19. Njim T, Mbanga C, Mouemba D, et al. Determinants of burnout syndrome among nursing students in Cameroon: cross-sectional study. BMC Res Notes 2018;11:450.

20. Wayne DW, Chad LC. Biostatistics: a foundation for analysis in the health sciences. 10 edn. New York: John Wiley \& Sons. 
21. Chirico F. Job stress models for predicting burnout syndrome: a review. Ann Ist Super Sanita 2016;52:443-56.

22. Magnavita N, Chiorri C. Academic stress and active learning of nursing students: a cross-sectional study. Nurse Educ Today 2018;68:128-33.

23. Sidana $\mathrm{S}$, et al. Prevalence of depression in students of a medical college in New Delhi: a cross-sectional study. Australas Med J 2012;5:247-50.

24. Vinodh RS, Pradeep C. Evaluation of burnout syndrome in medical students. Journal of Pharmaceutical, Chemical and Biological Sciences 2016;4:299-306.

25. Arthurs E, Steele RJ, Hudson M, et al. Are scores on English and French versions of the PHQ-9 comparable? An assessment of differential item functioning. PLoS One 2012;7:e52028.

26. Arnaud $A$, Issabelle $H$. Structural confirmation of the french version of the oldenburg burnout inventory (OLBI) Germany. $2013 \mathrm{http}: / / \mathrm{hdl}$. handle.net/2268/149404 (Accessed 09th Feb 2018).

27. Kroenke K, Spitzer RL. The PHQ-9: a new depression diagnostic and severity measure. Psychiatr Ann 2002;32:509-15.

28. Kroenke K, Spitzer RL, Williams JB. The PHQ-9: validity of a brief depression severity measure. J Gen Intern Med 2001;16:606-13.

29. Bursac Z, Gauss CH, Williams DK, et al. Purposeful selection of variables in logistic regression. Source Code Biol Med 2008:3:17.

30. Nwobi EA, Ekwueme OC, Ezeoke EA. Mental depression and coping strategies among medical students of University of Nigeria, Enugu campus. International Journal of Medicine and Health Development 2009;14.

31. Ibrahim MB, Abdelreheem MH. Prevalence of anxiety and depression among medical and pharmaceutical students in Alexandria University. Alexandria Journal of Medicine 2015;51:167-73.

32. Abdel Wahed WY, Hassan SK. Prevalence and associated factors of stress, anxiety and depression among medical Fayoum University students. Alexandria Journal of Medicine 2017;53:77-84.

33. Martini S, Arfken CL, Churchill A, et al. Burnout comparison among residents in different medical specialties. Acad Psychiatry 2004;28:240-2.
34. Pence BW, Gaynes BN, Atashili J, et al. Validity of an intervieweradministered patient health questionnaire- 9 to screen for depression in HIV-infected patients in Cameroon. J Affect Disord 2012;143:208-13.

35. Okasha A. Mental health in Africa: the role of the WPA. World Psychiatry 2002;1:32-5.

36. World Health Organisation. Burnout. Geneva: World Health Organisation, 2016.

37. Medicine USNLO. Depression: what is burnout? $2017 \mathrm{https}: / / \mathrm{www}$ ncbi.nlm.nih.gov/pubmedhealth/PMH0072470/.

38. Bouma J, Ranchor AV, Sanderman R, et al. llet meten van symptomen van depressie met de CES-D: een handleiding [the measurement of depression symptoms with the CES-D: a manual]. Groningen, The Netherlands: Noordelijk Centrum voor Gezondheidsvraagstukken, 1995.

39. Chiu LYL, Stewart K, Woo C, et al. The relationship between burnout and depressive symptoms in patients with depressive disorders. $J$ Affect Disord 2015;172:361-6.

40. Bullock G, Kraft L, Amsden K, et al. The prevalence and effect of burnout on graduate healthcare students. Can Med Educ $J$ 2017:8:90-108.

41. Frank R, Nixdorf I, Beckmann J. Analyzing the relationship between burnout and depression in junior elite athletes. J Clin Sport Psychol 2017;11:287-303.

42. Amani A. The health workers crises In Cameroon. [Public Health Thesis]: Georgia State University, 2010.

43. Simon GE. Treating depression in patients with chronic disease: recognition and treatment are crucial; depression worsens the course of a chronic illness. West J Med 2001;175:292-3.

44. Grenard JL, Munjas BA, Adams JL, et al. Depression and medication adherence in the treatment of chronic diseases in the United States: a meta-analysis. J Gen Intern Med 2011;26:1175-82.

45. DiMatteo MR, Lepper HS, Croghan TW. Depression is a risk factor for noncompliance with medical treatment: meta-analysis of the effects of anxiety and depression on patient adherence. Arch Intern Med 2000;160:2101-7. 